\title{
Investigating the Factors Affecting the Sustainable Management of Sporting Student Events Worldwide
}

\author{
Mohammad Saeid Kiani ${ }^{1, ~ *, ~ L e i l a ~ N a z a r i ~}{ }^{2}$, Leila Shahbazpour ${ }^{3}$ \\ ${ }^{1}$ Department of Sport Management, Islamic Azad University, Kermanshah, Iran \\ ${ }^{2}$ Department of Sport Management, Razi University, Kermanshah, Iran \\ ${ }^{3}$ Department of Sport Management, Shahrood University of Technology, Shahrood, Iran
}

Email address:

mohammadsaeidkiani@gmail.com (M. S. Kiani), leilanazari2020@gmail.com (L. Nazari), leila.shahbazpour1311@gmail.com (L. Shahbazpour)

${ }^{*}$ Corresponding author

\section{To cite this article:}

Mohammad Saeid Kiani, Leila Nazari, Leila Shahbazpour. Investigating the Factors Affecting the Sustainable Management of Sporting Student Events Worldwide. International Journal of Sports Science and Physical Education. Special Issue: Sustainable Development in Tourism Sports Events. Vol. 4, No. 2, 2019, pp. 28-32. doi: 10.11648/j.ijsspe.20190402.12

Received: August 5, 2019; Accepted: September 25, 2019; Published: October 9, 2019

\begin{abstract}
The purpose of the present study was to investigate the factors affecting sustainable management in sporting events for students worldwide. The method of this study is a review study and has become a challenging issue due to the importance of environmental issues in the world and the role of the environment in researcher has studied and translated related articles and books on sustainable management at sporting events from 2000 to 2019. According to the findings, sustainable development is a process of change that aligns resource utilization, investment management, technological development orientation and organizational change with current and future needs. Identifying and explaining students' attitudes to the environment, as an informed and influential part of society, is an essential and important step in environmental policy making and generating awareness of the environment and its dangers and how to protect the environment. The researcher concludes that resolving the contemporary environmental crisis requires the development of student participation to preserve the environment in sporting events so that by increasing knowledge of changing values and enhancing change potential, appropriate conditions are created for solidarity and harmony between students and the environment. Be provided. The more students use information resources such as the visual media, the written, their environmental attitudes and performance in sporting events, the better environmental factors.
\end{abstract}

Keywords: Sustainable Development, Sports Event, Student Event, Environment

\section{Introduction}

Nature and the environment are a God-given blessing that comes from the set of organisms, resources and factors and conditions of harmony that exist and depend on each living being. The environment is the place of living and providing the most basic human needs, but unfortunately during its reign over humans, the planet was used indiscriminately without any planning of natural resources, causing dangerous contaminations in the soil, climate and destroying the ability to live. The environment has paid off.

Culture is a key driver of sustainable development and environmental protection. Improving the environment is linked to human culture, so it is imperative that environmental ethics exist across all segments of a society. Expectations and aspirations of humans must be defined in a way that is not solely focused on themselves or their presentday lives. Some scholars have defined social ethics as the ability to prefer one's will to another's. From this point of view, those who only see their own interests and consider their desires and desires are less likely to benefit from ethics. Protecting the environment requires the existence of ethical people in society. Failure to comply with environmental ethics will make future generations face numerous challenges and blame us. The development of ethics is a gradual, slow, and difficult task, because many do not need it, and many resist it because of their preference for personal gain. 
Currently, the ultimate goal of environmental protection is to achieve sustainable development in the form of economic programs consistent with the principles of environmental protection and to prevent the degradation and depletion of renewable and non-renewable resources. Therefore, in order to fundamentally address critical environmental problems, macro and infrastructure development perspectives must be designed in accordance with environmental protection laws and any future economic, social and cultural development policies and plans.

The country should build on the foundations of environmental protection, natural resources and rational utilization of these resources with a view to balancing and proportionating environmental regulations and sustainable development. Today, the state of the environment, water, energy, and energy is complex and ambiguous, which has made all environmentalists think. For this reason, every effort is being made in today's world to use every tool to improve the environment and avoid wasting water, energy and more. Asking this question may seem a bit strange, how can sports have an environmental and energy impact; for example, what role can football play in protecting the environment, such as football with millions of fans around the world? Sports activities bring people together in one place, which in turn has negative externalities such as noise pollution, misconduct, waste, air pollution, and harsh lighting. These reasons have made many urban residents who wish to have access to recreational and sporting facilities lack the desire to live and live in close proximity [1].

Environmental literacy students are an essential part of sustainable societies [2]. The university student population, which often lacks sustainable knowledge, can improve their behaviors and reduce the overall environmental impact of universities [3].

Sport organizations place considerable importance on environmental sustainability (ES), underlining a movement away from exploiting to protecting the environment. Correspondingly, higher education has recognized the need to include ES in curricula [4].

The environment in which we live actually affects all of our physical activity. The effects of the environment on the human life cycle cannot be ignored. So we have to accept the fact that the environment plays an important role in all the interactions of the present age [5]. In this regard, we review the history of the World Student Championships and its members and its members. The International Federation of Student Sports (FISU) was formally established in 1949.

But its history goes back to the 20s [6]. The first Universal Student Games were held in Paris in 1923, led by a Frenchman named Jean-Pete Jean. The first formal physio congress was held in Warsaw in 1924, attended by many countries. From 1925 to 1939 several major sporting events were organized by the International Confederation of Students in Rome, Prague, Paris, Darmstadt, Budapest, Turin and Monaco.

After World War II and the multi-year stoppage of competitions and sports activities in the world in 1949, the
Student Sports Federation officially started in Luxembourg and held its first international university sports conference. The conferences were held in the cities of Marano, Luxemburg, Dortmund and Vassen Sebastian. In a new move in 1957, at the invitation of the French Academic Sports Federation, Fiso organized a tournament that brought together students from the two blocks of the West and East. After the conference there was a great desire to hold an international competition for students from all over the world. In 1959, Fizo and the World Students' Union agreed to jointly participate in competitions held by the Italian Sport Organization in Turin under the name Universiade. The Winter Universities also experienced similar success, expanding the range of college sports that led the physio to complete the Universal Student Competition since 1960 to complete the Universiade program. A spirit of understanding and peace come together to achieve high technical results. As a leading student sport organizer, Fizo has a flexible and competent structure in the world of multidisciplinary competitions [7].

Physio Structure: Physio is currently represented in various sectors including the General Assembly of Physio in more than 150 countries, the Executive Committee with 23 members and various committees including the International Technical Committee (Summer and Winter Games), Sports Competitions (CTI), The Medical Commission (CT), the International Commission on Control (CIC), the Commission on Academic Sport Studies (CESU), the International Commission on Press (CDI), the Marketing Commission, the Commission on History and... High value.

\section{Methodology}

This research is a review study and focuses on the importance of environmental issues in the world and the role of the environment in sport. This topic is now becoming a challenging topic and has an important role to play in sporting events. The subject of the study of factors affecting sustainable management in world student sporting events is a review of past researches that have done little research on sustainable management in student world events (physio) and the researcher examines the history of world student competition and its role and importance. The environment has been involved in these competitions and in promoting sustainable management in this series of global events, and its research findings by studying and translating articles from 2010 to 2019 on environmental and sporting events and global events especially in the field. Students have used. This research is done by reviewing the research and referring to library sources and translating and reviewing Latin articles.

\section{Findings}

Sustainable development is a process of change that addresses resource utilization, investment management, technological development orientation, and organizational change while meeting current and future needs. In this 
regard, identifying and explaining students' attitudes toward the environment, as an informed and influential part of society, is an essential and important step in environmental policy making and generating awareness of the environment and its dangers and how to protect the environment [8]. Since ancient times, people have been entertained by sports Exercise is about health, with the best athletes competing in physical form, but strangely, even though sports can promote health, they can work for an environment where it is good for health to have some damage, and playing sports can have a potential impact on the environment. Ski slopes, for example, disrupt alpine ecosystems, expand golf courses throughout the land, and consume a large amount of pesticides and water, while parking for stadiums and arenas levels they produce a complex. Major sporting events use energy, emit greenhouse gases, and generate large waste bins (Super Bowl 2016) in Detroit, 500 tonnes of greenhouse gas emissions (from transportation and utility use), while the 2004 Summer Olympics in Athens produced one million tonnes in two weeks, almost similar to what a city of one million emits over a similar period. Each game during the 2006 FIFA World Cup in the summer will produce about 3 million kilowatt hours of energy (similar to 700 European families annually), and about 5 to 10 tonnes of waste [9].

There are two relevant perspectives on sport and the environment. The first is an Inside-Out perspective on how organizational personnel understand how their activities affect the environment. A second perspective is overseas, in which issues related to the external environment and related matters (eg government regulations) affect the performance of an organization. In sports, much of the conceptualization, research, and knowledge of these topics encompasses the Inside-Out perspective [10]. With the growth of sports leagues around the world, the energy consumed by national and international sports competitions will continue [11]. During the 2012 Summer Olympics in London, 10,500 athletes participated and 500,000 traveled to attend them. Seventy thousand people visited New Orleans to attend Super Bowl, but more people visited the city because of the events surrounding Super Bowl but had no tickets to the game. It is estimated that each match at the 2006 FIFA World Cup consumes three million kilowatt hours of energy and generates five to ten tonnes of waste - and this was in line with an environmental program prepared by FIFA before the tournament. These events allow millions of people around the world to stay home, but still involve a significant amount of resource consumption at millions of parties around the country and overall home visits. Events require parking, which is used for construction and maintenance of land and resources. Due to the higher freight status, considering freight when designing facilities, improved shipping options (meaning some fans and participants travel to these games by bus, bike or walk and they use it, but car travel is followed by air travel. The rules and regulations regarding the construction of sports facilities and their performance are as amenable to friendly purposes. Since the 1970s and the passage of the National Environmental Policy Act, federal agencies have had to consider the environmental impact of any federal action [12]. Eight countries follow this lead, often conducting environmental impact studies and reports. In 2009, the city of Santa Clara, California, did one of these studies to prepare a new stadium for the San Francisco 49ers. The report was sent to more than 30 organizations, including the US Army Corps of Engineers, the California Highway Patrol, and the Cupertino Planning Department. Comments on the study were requested and included in the final report. The study results provide a comprehensive analysis of the environmental impacts of the new stadium. This small example is part of a broad network of laws and regulations governing the construction and operation of organizations in the United States. State environmental policy measures require environmental study and planning prior to any state action, although this may vary. SEPA 8 also ensures that state natural resources agencies conduct environmental reviews of proposed projects [13].

While there are mechanisms for delaying or exempting environmental review, this review cannot be fully skipped unless SEPA demonstrates the process of doing so (for example, timing requirements for placement of a construction project and Instrument in votes). The Green Sports Alliance aims to understand how the games we play can affect them and create awareness of the environment to promote change. It seems that enjoying the playground can be a far more effective way of spreading our message about our natural resources than the classroom. Naturally, sports participation and behavior affect the environment and in turn affect it. Environmental sustainability is an important part of any Olympic Games project. The Organizing Committee functions at every local, national and international level to ensure that environmental sustainability standards are fully involved in game planning and delivery and beyond. Exercise, like any other human activity, is in the physical environment and is bound to affect and be affected by it. The origins of global environmental issues must be traced back to local environmental conditions, and the interaction of sports communities with the environment in which they operate should be analyzed.

Additional local, state, and federal laws and regulations on environmental issues are also part of the process, which is why staff at sports organizations specialize in organizations such as the Natural Resources Defense Council (NRDC) and the US Green Building Council. Along with regulatory guidelines set up by groups such as the International Olympic Committee, sports personnel have a complex task of fulfilling the organization's goals while being responsible for environmental affairs. Finally, the Green Nonprofit Sports Association was formed in 2010 with a mission to help sports teams, venues and leagues improve their environmental performance.

The Olympics, as the world's largest human and sporting event, have also placed a great deal of emphasis on environmental protection and green space design, as the Sydney Olympics became known in 2000 as a green Olympics in keeping with these principles [14]. 


\section{Conclusion}

Resolving the contemporary environmental crisis requires the development of student competence and participation to protect the environment in sporting events so that by increasing knowledge, changing values and enhancing competence, appropriate conditions are provided for establishing a solidarity and harmony between students and the environment. Research has been conducted to investigate sustainable management of student events worldwide, and the results show that there is a direct relationship between attitude and environmental performance among students in sporting events. In a study conducted by the researcher in this field in Brazil, The results are shown between attitude and AS There is a significant difference between students 'environmental performance. Students' environmental attitudes and practices also differed based on their use of information resources, indicating that students were more likely to use information resources such as visual media, print media. Their attitudes and environmental performance improve at sporting events, and the more positive a student's perception of environmental performance is.

The researcher concludes that environmental education at all levels and laws of environmental protection must be observed at all sporting events (national and international).

1) All components of the planet are interdependent and every decision today has an impact on the future of the environment.

2) All students need to be educated in environmental, social, cultural, and economic decisions.

3) All students must consider environmental issues in their decisions.

4) Interdisciplinary partnerships between physical education and the environment are essential to maintain sustainable management.

Although exercise is not one of the biggest environmentalists, it can cause a great deal of damage to the environment [15]. Today's environmental crises have become a global problem and there are widespread efforts by countries and international forums to address pollution and environmental degradation. If managers and operators of sports, athletes and spectators understand and accept that their more responsible behavior has a positive impact on the environmental conditions of the venue, the damage to the environment will be reduced. The very important role of sport and its symbols can also be used to raise environmental awareness, improve the performance and daily activities of millions of people who are part of the industry. Sport and the environment are closely intertwined and are referred to as a tool for achieving sustainable development. Since the Olympic Charter of Correction and the Environment after sport and culture has become the third pillar of the Olympic Charter, significant efforts have been made to protect the environment. There is nowadays evidence of increased environmental sustainability of sports complexes. Consumption of water is consumed, clean energy and solar energy are used, grassland water use in many places is managed through drip irrigation, pesticide consumption is declining.

The halls have a Sustainable Management Certificate, are environmentally friendly flooring used, environmental considerations and conservation obligations are among the important criteria for awarding hosting privileges to Olympic Games volunteer cities. Based on findings, participation and performance Sport Has a Great Impact on the Natural Environment Many student athletes at all levels of the industry are trying to understand the environmental impact of their activities.

Green Sport Alliance is a nonprofit organization designed to facilitate dialogue and information sharing among its members. As a result, to be effective and sustainable in these efforts, student sports personnel must turn environmental strategic planning into part of overall organizational operations. Promoting sustainable management of sporting events for students worldwide is a major step forward in protecting the environment and protecting the Earth's resources as students come from a specific stratum of human societies and become major pillars of a comprehensive education such as the great professors and the future. Protects the environment at all levels and $b$ The title of promoter is in the field of environmental protection in every field and should be given equal importance in the field of sustainable development in sporting events of world students as in other world events as in this World Federation according to the findings of 150 countries It is a member that is a great figure for sustainable development in the sporting event, and that it is organized regularly and according to the schedule and calendar of all its competitions and is of particular importance [16].

\section{References}

[1] FIFA and the Environment. [online] (2013) www.fifa.com/aboutfifa/socialresponsibility/environmental.html

[2] Shephard, K., J. Harraway, B. Lovelock, S. Skeaff, L. Slooten, M. Strack, M. Furnari, and T. Jowett. 2014. "Is the Environmental Literacy of University Students Measurable?" Environmental Education Research 20 (4): 476-495.

[3] Lauren E. Mullenbach \& Gary T. Green (2016): Can environmental education increase student-athletes' environmental behaviors? Environmental Education Research, DOI: 10.1080/13504622.2016.1241218.

[4] Trendafilova, Sylvia, Graham, Jeffrey and Ziakas, Vassilios (2018) Examining the landscape of environmental sustainability in sport management education. In: Applied Sport Management Association Conference 2018, 15-17 February 2018, Waco, Texas.

[5] Baluchi R, 2006, Sport and Environment, First National Conference on City and Sport, Tehran.

[6] National Federation of University Sports FISU http://www.iusf.ir/About/History.

[7] Houghton, RA. Balancing the global carbon budget. Annual Review of Earth and Planetary Sciences 35, 313-347. (2007). 
[8] Sadeghi S, Pazokinejad Z. An Analysis of Social Factors Affecting Students' Attitude and Environmental Performance. Sociology Publications 2014.

[9] Dino M. Minolia, Mark M. H. Goodeb, Aidan W. Metcalfec. (2018). Are sport tourists of an environmental mindset to drive the green? The case of golfers. Tourism Management Perspectives 25 (2018) 71-79.

[10] Kiani, M; Nazari L and Shahbazpour L, 2019, Environmental Awakening: Using a New Strategy to Promote Environmental Culture in Sport, Third International Conference on Applied Research in Physical Education, Sport Sciences and Championships, Tehran - Allameh Tabatabai University, Permanent Secretariat of the Conference, with the support of Associations and Departments of Iranian Universities, https://www.civilica.com/Paper-PESSO03PESSO03 030.html.

[11] Dolles, H \& Söderman, S. Addressing ecology and sustainability in mega-sporting events: The 2006 football World Cup in Germany. Journal of Management \& Organization 16, 587-600. (2010).

[12] Kiani, M; Nazari L and Shahbazpour L. Sport Tourism and Sustainable Local Development for Host Cities for Sporting Events. American Journal of Sports Science 2019.

[13] https://www.civilica.com/Paper-NCCS01-NCCS01_029.html

[14] Schmidt, C. Putting the Earth in play: Environmental awareness and sports. Environmental Health Perspectives 114, A286-A295. (2006).

[15] Ekhtiari N, Eidi H, Shabani Moghaddam K. Explaining the Model of Factors Affecting the Development of Environmental Culture in Sport. Applied Research in Sport Management. 2018.

[16] Porter, M \& Reinhardt, F. A strategic approach to climate change. Harvard Business Review 85, 22-26. (2007). 